\title{
Avaliação do conhecimento explícito da língua: verbos de comando de provas do Ensino Básico
}

\section{Pruebas de educación básica para evaluar el conocimiento explícito de la lengua: análisis compositivo y curricular}

\section{Sónia Valente Rodrigues}

Faculdade de Letras e Centro de Linguística da Universidade do Porto srodrigues@letras.up.pt

ORCID ID: http://orcid.org/0000-0003-0571-024X

\section{Isabel Margarida Duarte}

Faculdade de Letras e Centro de Linguística da Universidade do Porto iduarte@letras.up.pt

\section{ORCID ID: http://orcid.org/0000-0001-7908-5649}

DOI: $10.17398 / 1988-8430.35 .2 .137$

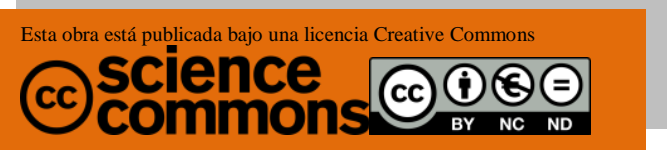

Fecha de recepción: $27 / 05 / 2021$ Fecha de aceptación: 22/07/2021

Valente Rodrigues, S, y Margarida Duarte, I. (2022). Avaliação do conhecimento explícito da língua: verbos de comando de provas do Ensino Básico. Tejuelo, 35(2), 137-172.

Doi: https://doi.org/10.17398/1988-8430.35.2.137 
Resumo: Este artigo apresenta uma investigação sobre provas de avaliação de conhecimentos gramaticais aplicadas por professores a alunos dos $7 .^{\circ}, 8 .^{\circ}$ e $9 .^{\circ}$ anos de escolaridade. Depois da constituição do corpus, analisaram-se as tarefas solicitadas aos alunos, para identificar os conteúdos e os processos gramaticais avaliados. Os resultados permitem três observações: (i) as operações envolvidas na execução da tarefa solicitada pelo verbo comando restringem-se a um conjunto limitado de que se destacam verbos com alta frequência de uso, como classificar, indicar e identificar; (ii) os elementos que pormenorizam a tarefa (verbos de comando e conteúdo avaliado) têm uma clara uniformidade durante os três anos (7, 8, 9); (iii) os ítems de avaliação revelam uma clara imitação dos objetivos curriculares da disciplina de Português. Os resultados obtidos permitem concluir que, no desenvolvimento do conhecimento linguístico explícito, existe um isomorfismo entre os objetivos, as provas de avaliação externa e as provas utilizadas pelos professores quanto ao uso de elementos de avaliação da aprendizagem, que validam um conjunto muito restrito de operações mentais.

Palabras clave: conhecimento explícito da língua, avaliação da aprendizagem, elaboração de testes .
Abstract: This article presents a research on the tests evaluating grammatical knowledge in Portuguese as a mother tongue applied by teachers to students from three years of schooling (7th, 8th, and 9th grades) to identify the assessed contents and grammatical processes. Once the corpus was established, and the tasks requested from the students were analyzed, the results show three observations: (i) the operations involved in the execution of the task requested by the command verb are restricted to a closed set of verbs with a high frequency of use such as classifying, indicating and identifying; (ii) the items that enunciate the tasks (command verbs and assessed content) present, over the three years (7th, 8th, 9th), a clear standardization; (iii) the assessment items reveal a clear mimicry of the curricular goals of the Portuguese subject. The results obtained allow the conclusion that, in the development of explicit knowledge of the language (grammar), there is an isomorphism between the goals, the external assessment tests and the tests used by teachers in the use of learning assessment items, which value a very limited set of elementary operations.

Keywords: explicit knowledge of the language, assessment of learning, test construction. 


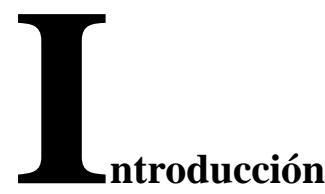

A avaliação das e para as aprendizagens, desenvolvida em contexto de sala de aula, "é um processo de natureza eminentemente pedagógica cujo fundamental propósito é melhorar o que e como se ensina e o que e como se aprende" (Fernandes, 2015, p. 13), tendo em mente o currículo prescrito ou enunciado'. Sendo parte intrínseca do ensino e da aprendizagem, a avaliação está profundamente ligada às estratégias pedagógicas da aula e ao curso de trabalho didático desenvolvido pelo professor com os seus alunos. Neste âmbito, entendemos a avaliação no seu sentido geral de "recolha sistemática de informação sobre a qual se possa formular um juízo de valor que facilite

\footnotetext{
${ }^{1}$ Neste estudo, atendemos sobretudo ao que, em certas tipologias, é designado como "currículo prescrito" (Pacheco, 2001; Roldão, 1999), visível nos planos de estudos adotados e nos respetivos discursos legitimadores. De acordo com Roldão e Almeida (2018), é importante compreender o currículo prescrito ou o currículo enunciado "por revelar intenções educativas legitimadas socialmente, cuja concretização, nunca neutral, se operacionaliza na prática de sala de aula, ou, em linguagem curricular, no currículo implementado, de que desejavelmente, se espera que resulte o currículo aprendido ou real, a apropriar pelos aprendentes, em nome da sua necessidade e relevância atribuída que consubstanciam a sua legitimação. (pp. 91-92)
} 
a tomada de decisões" (Peralta, 2002, p. 27), decorrente das interações e dinâmicas que se estabelecem entre professores e alunos nas salas de aula. Daí que seja possível ao professor recorrer a grande diversidade de técnicas e de instrumentos de avaliação, em função das finalidades, do objeto de avaliação, do contexto específico de aplicação, dos participantes, das modalidades implementadas.

Apesar da diversidade de instrumentos e técnicas passíveis de utilização pelos professores, é conhecida a importância conferida por pais, professores e alunos ao teste como um dos instrumentos mais recorrentes na avaliação interna de aprendizagens escolares, sendo usado para «recolher informação sobre o aproveitamento dos alunos/formandos quanto às capacidades desenvolvidas e aos conhecimentos adquiridos numa perspetiva do seu desempenho máximo e não do desempenho típico, isto é, do que habitualmente vão demonstrando e revelando saber.» (Neves \& Ferreira 2015, 82). Também conhecido como prova de «papel e lápis», requer dos alunos a produção de respostas escritas a itens também apresentados por escrito (Neves \& Ferreira, 2015:52). Os "itens de avaliação" (ou simplesmente "itens") referem as questões que constituem o teste, isto é, os enunciados que indicam "de forma clara as tarefas a realizar pelos respondentes" (Neves \& Ferreira 2015, p. 91).

A relevância da análise dos testes de avaliação elaborados e usados pelos professores nas suas aulas deriva da importância que é concedida por todos os envolvidos nas aprendizagens escolares (mais diretamente, encarregados de educação, docentes e discentes) e do efeito que o feedback dele resultante potencia. Assumir como objeto de estudo os testes utilizados pelos professores nas diversas dinâmicas das aulas ao longo do ano permite compreender melhor diferentes questões do conhecimento profissional docente, como, por exemplo, os procedimentos técnicos de elaboração de testes usados pelos professores na prática profissional, as fontes a que recorrem para a construção, as aprendizagens do currículo escolhidas pelos professores para serem objeto de avaliação através desse instrumento específico. E, no fundo, que currículo valorizam os professores através da avaliação das aprendizagens dos alunos, tendo em conta que, como afirma Lauren 
Resnick (1987), citada em Fernandes (2019, p. 656), "só se consegue obter aquilo que conseguimos avaliar e, consequentemente, não se obtém o que não se avalia”.

De entre as várias questões referidas², deter-nos-emos neste estudo na que diz respeito à relação entre testes, usados pelos professores na avaliação interna, e provas de exame nacional, aplicados na avaliação externa. Provas (de exame nacional) e testes (de avaliação interna) pertencem ao mesmo conjunto de instrumentos de recolha de informação relativa às aprendizagens, designado por ser de "papel e lápis", mas, ao contrário dos testes, a avaliação externa "é de responsabilidade de uma entidade qualquer externa à escola (Instituto de Avaliação, Ministério da Educação, Agência Independente de Avaliação) e tem como principal propósito medir, num dado momento, o que os alunos sabem e são capazes de fazer em um ou mais domínios do currículo de um ou mais anos de escolaridade." (Fernandes, 2019, p.

2 A clareza dos itens de avaliação é uma das dimensões de estudo a ter em consideração no âmbito da didática, dadas as questões suscitadas pelos resultados de investigações recentes, que tornam evidentes a ambiguidade e a variação semântica e pragmática de itens avaliativos, o que poderá explicar dúvidas e indefinições nas respostas que os alunos dão em momentos de avaliação. Em 2016, um grupo constituído por investigadores e professores dos ensinos básico e secundário de diferentes disciplinas (Português, Matemática, Físico-Química e Biologia) analisou os testes de avaliação produzidos e aplicados pelos respetivos professores às turmas do 7..$^{\circ}$ ano de escolaridade das referidas disciplinas, numa escola pública, durante um ano letivo (Duarte, Rodrigues, Machado, Guedes e Toriz, 2016). Este estudo, com incidência nos verbos instrucionais dos itens de avaliação, revelou a existência de um conjunto fechado de verbos de instrução utilizado em todas as disciplinas mencionadas, com divergências de sentido nos diferentes usos. Por exemplo, o verbo "explicar" é empregue, nuns contextos, como solicitação de um texto explicativo e, noutros, como sinónimo de "definir", "parafrasear", "distinguir", "caracterizar", requerendo dos alunos um texto breve entendido como uma definição, uma paráfrase, a explicitação de uma relação de causa e efeito entre dois elementos ou uma descrição. Também se verificou que os professores de uma mesma disciplina utilizam, para obter a mesma resposta, verbos de instrução diferentes (por exemplo, "justificar" e “explicar" ocorrem como sinónimos, "calcular" e "determinar" também). Em 2018, foi publicada uma análise aprofundada dos valores semânticos e pragmáticos de "explicar" como verbo de instrução, em testes de avaliação, em contexto educativo (Rodrigues, Duarte \& Silvano, 2018), com resultados análogos à anterior. 
645). As provas elaboradas neste âmbito, de integral responsabilidade de uma instituição externa às escolas, ao contrário dos testes elaborados por cada profesor para cada uma das suas turmas, em função do percurso de aprendizagem em desenvolvimento, são estandardizadas e de aplicação universal, estando a sua realização condicionada a constrangimentos de espaço, de tempo e de modo.

Apesar de terem finalidades e condições de aplicação muito diferentes dos processos de testagem utilizados pelos professores, as provas de exames nacionais exercem uma influência muito forte sobre o «desenvolvimento de práticas de avaliação em sala de aula que mimetizam, no seu conteúdo e na sua forma, a avaliação externa.» (Barbosa \& Neves, 2006, p. 221). Dos efeitos nefastos da avaliação externa sobejamente estudados e documentados, destacamos três: "o chamado 'estreitamento' ou 'afunilamento' do currículo, que consiste na tendência de os professores ensinarem para o que consideram que vai ser perguntado nos exames." (Fernandes, 2019, p. 649); em certos contextos, os professores "tendem a utilizar mais tempo a 'ensinar para o teste' e, por isso, o empobrecimento do currículo é superior" (Fernandes, 2019, p. 649); as provas de avaliação externa "condicionam de forma mais ou menos significativa a seleção das propostas de trabalho que se propõem aos alunos, levando muitos professores a utilizarem frequentemente tarefas com questões semelhantes às que normalmente aparecem nos exames" (Fernandes, 2019, p. 649).

O conhecimento explícito da língua, competência nuclear da disciplina de Português (Rodrigues 2017, Costa 2020), é objeto de avaliação externa ao longo de toda a escolaridade obrigatória (nos três ciclos do ensino básico e no ensino secundário). As provas que lhe dão corpo têm sido objeto de atenção de diferentes investigadores (Rei, 2004; Silva, 2009; Silva \& Sousa, 2009; Silva \& Silva, 2011; RioTorto, 2011; Tapadas, 2016; Rodrigues, 2019) no sentido de conhecer o currículo gramatical aprendido ou real, em função do que se procurou legitimar como necessário ou relevante através do currículo enunciado ou prescrito ${ }^{3}$. As conclusões destas investigações destacam como objeto

\footnotetext{
${ }^{3}$ Rei (2004) apresenta os dados da análise dos exames nacionais entre a década de 30 e a de 90 do século XX. Silva \& Sousa (2009) analisaram as seguintes provas 
de avaliação predominante, na disciplina de Português, aprendizagens gramaticais associadas à morfologia e à sintaxe e processos como o do reconhecimento, identificação e classificação de elementos.

Tendo em conta os resultados convergentes destas investigações centradas na avaliação externa do conhecimento gramatical, realizada nos diversos níveis de escolaridade (do $2 .^{\circ}$ ao $12 .^{\circ}$ ano de escolaridade) ao longo de um período considerável (de 2001 a 2018), é seguro afirmar que são conhecimentos gramaticais muito valorizados os que se relacionam com a morfologia e a sintaxe, sobretudo os que se prendem com classificação gramatical (classes de palavras, classificação de orações) e de funções de constituintes na frase.

Apesar de genericamente comprovado o efeito mimético dos exames nacionais nos testes de avaliação interna nas escolas (Barbosa \& Neves, 2006; Fernandes, 2019) e empiricamente atestado pela nossa experiência de trabalho, na verdade esse fenómeno não está comprovado por estudos baseados no agir didático concreto dos professores em sala de aula, pelo menos em Portugal. O presente estudo tem, por isso, por finalidade responder à questão seguinte: qual o grau de mimetismo entre os itens de avaliação usados pelos professores para verificarem o conhecimento gramatical dos alunos e os usados nas provas de avaliação externa?

correspondentes ao ano letivo 2008/2009: Prova de Aferição de Língua Portuguesa do 2. ${ }^{\circ}$ ciclo, Prova Escrita de Língua Portuguesa do 3. ${ }^{\circ}$ ciclo (Prova 22) e Prova Escrita de Português do $12 .^{\circ}$ ano (Prova 639). Silva \& Silva (2011) analisaram provas de 2009/2010: Prova de Aferição do $1 .^{\circ}$ ciclo do ensino básico, Prova de Aferição do 2. ${ }^{\circ}$ ciclo do ensino básico, Exame Nacional do 3..$^{\circ}$ ciclo do ensino básico, Exame Nacional do Ensino Secundário. Silva (2009) analisou Provas de Aferição e Exames Nacionais de Português do $9 .^{\circ}$ ano correspondentes a 7 anos letivos sucessivos, de 2001 a 2008. Rio-Torto (2011) analisou Exames Nacionais de 9..$^{\circ}$ ano. Tapadas (2016) analisou a avaliação do conhecimento gramatical em provas realizadas durante 10 anos: Exame Nacional de Língua Portuguesa, de 2005 a 2007; Prova Escrita de Língua Portuguesa, de 2008 a 2011; Prova Final de Língua Portuguesa, de 2012; Prova Final de Português, de 2013 e de 2014. Todas as provas analisadas nos trabalhos mencionados são de avaliação externa. 


\section{1.- Objeto e objetivos do estudo}

Para o desenho da investigação orientada pela questão acima referida, foi necessário proceder a uma restrição do âmbito de estudo e a uma formulação de duas questões mais específicas:

1 - Que aprendizagens são objeto de avaliação pelos professores de Português, no domínio do conhecimento explícito da língua, no $3 .^{\circ}$ ciclo do ensino básico?

2 - Que relação se pode estabelecer entre os itens de avaliação do conhecimento da língua dos testes dos professores, as metas curriculares da disciplina de Português e os itens das provas de avaliação externa?

A restrição da questão ao $3 .^{\circ}$ ciclo do ensino básico justifica-se pela conveniência do estudo, uma vez que, à época da sua idealização, uma das investigadoras se encontrava a trabalhar como professora de Português de $3 .^{\circ}$ ciclo do ensino básico.

Para responder às questões, foram definidos os seguintes objetivos:

(i) analisar os itens para recolha de informação pelos professores sobre o conhecimento explícito da língua dos alunos;

(ii) determinar o conhecimento explícito da língua que é objeto de avaliação no corpus;

(ii) relacionar os itens de avaliação dos testes com as metas curriculares de Português;

(iii) relacionar os resultados com estudos sobre a avaliação do conhecimento gramatical em provas de avaliação externa. 


\section{2.- Estudo}

\section{1.- Corpus}

O corpus reuniu 445 itens extraídos de 86 testes de avaliação, usados por 10 professores de Português, no ano letivo 2017/2018 para avaliação formativa e sumativa das aprendizagens de alunos dos três anos do $3 .^{\circ}$ ciclo do ensino básico $\left(7 .^{\circ}, 8 .^{\circ}\right.$ e $9 .^{\circ}$ anos), numa escola pública do distrito do Porto.

Os 445 itens constitutivos do corpus dizem respeito exclusivamente à avaliação do conhecimento explícito da língua e pertencem a duas categorias: itens de escolha múltipla e de resposta curta $^{4}$. A tabela 1 apresenta os dados por ano de escolaridade.

\section{Tabela 1}

Número de testes e de itens por ano de escolaridade

\begin{tabular}{lcc} 
Anos & $\mathbf{N}^{\mathbf{o}}$ de testes & $\mathbf{N}^{\mathbf{o}}$ de itens \\
\hline $7 .^{\mathbf{o}}$ & 29 & 126 \\
\hline $8 .^{\mathbf{o}}$ & 29 & 144 \\
\hline $9 .^{\mathbf{o}}$ & 28 & 175 \\
\hline Total & 86 & 445 \\
\hline
\end{tabular}

Fonte: elaboração própria.

\section{2.- Metodologia}

Os procedimentos realizados para a análise foram os seguintes. Em primeiro lugar, procedeu-se à extração dos itens relacionados com o conhecimento explícito da língua do conjunto de cada um dos testes de avaliação da disciplina de Português, uma vez que cada um é composto por diferentes secções, de acordo com as competências linguísticas a avaliar (oralidade, leitura, escrita, conhecimento explícito da língua). Em segundo lugar, realizou-se a análise de cada um dos itens em três fases:

\footnotetext{
${ }^{4}$ Estas categorias correspondem à tipologia referida por Neves \& Ferreira (2015): «Um item de escolha múltipla é constituído por um tronco seguido das opções de resposta em que se inclui a resposta correta.» (p. 92); «Um item de resposta curta solicita uma resposta correcta, estruturada de forma simples e clara, a qual consiste, por exemplo, numa palavra, numa frase, num número ou numa fórmula.» (p. 107).
} 
a) identificação dos verbos de comando5, que indicam aos alunos a tarefa a realizar na resposta; b) análise dos conteúdos gramaticais associados aos verbos de comando; c) comparação dos itens analisados com as metas curriculares de Português ${ }^{6}$.

Para a identificação dos verbos de comando, houve necessidade de distinguir aqueles que enunciavam uma tarefa relacionada com o conhecimento gramatical a avaliar (exemplo A) daqueles que indicam o procedimento a realizar na execução da tarefa (exemplo B). No exemplo B, o enunciado sublinhado não é considerado na contagem dos verbos de comando relacionados com a tarefa a executar pelo aluno; trata-se, na verdade, de um procedimento preparatório que é obrigatório como condição para a realização da tarefa a avaliar ('indicar a classe e subclasse de palavras').

\section{Exemplo A}

Item de teste

Transforma a frase ativa que se segue numa frase passiva.

Naquele dia, a oferta do balão tinha proporcionado um momento memorável.

Fonte: Doc_01 - teste do $8 .^{\circ}$ ano

\section{Exemplo B}

Item de teste

1. Lê o excerto do texto que se segue e indica a classe e subclasse das palavras sublinhadas.

Não me lembro se ele era verde ou vermelho, amarelo ou azul, ou branco simplesmente. O que depois se passou iria apagar para sempre da minha memória a cor que deveria ter-me ficado pegada aos olhos para sempre, uma vez que aquele era nada mais nada menos que o meu primeiro balão em todos os seis ou sete anos que levava de vida.

Fonte: Doc_02 - teste do $8 .^{\circ}$ ano

Verbos de comando ou verbos operatórios são os verbos que, em cada item, enunciam a(s) tarefa(s) a realizar pelos alunos. São geralmente flexionados no modo imperativo ou no presente do conjuntivo.

- O Programa e Metas Curriculares de Português do Ensino Básico é um dos documentos de referência no ensino de Português no ano 2017/2018. 
Foi ainda necessário ignorar formas de comando em enunciados compostos por mais do que uma frase ou, mesmo com uma única frase, com mais do que um comando. Veja-se o exemplo C.

\section{Exemplo C}

Item de teste

3. Reescreve a frase abaixo, substituindo as expressões sublinhadas pelas formas adequadas do pronome pessoal. Faz as alterações necessárias.

3.1. "Mas não é possível ignorar os sentimentos, por muito injustos ou ingratos que possam parecer."

3.2. A escrita ajudou Anne Frank a sair "das profundezas do desespero".

3.3. "os nossos estados de espírito têm tendência para nos afetar bastante".

Fonte: Doc_04 - teste do $8 .^{\circ}$ ano.

Em C, existem três instruções: duas na primeira frase e uma na segunda:

a) a primeira enunciada através do modo imperativo "Reescreve a frase abaixo";

b) a segunda, mediante o gerúndio - "substituindo as expressões sublinhadas pelas formas adequadas do pronome pessoal";

c) a terceira, em modo imperativo - "Faz as alterações necessárias."

Destas três instruções, duas dizem respeito a procedimentos a utilizar pelos alunos para a execução da tarefa solicitada, que é, na verdade, substituir as expressões sublinhadas pelas formas adequadas do pronome pessoal. Para a análise que realizámos só esta última foi contabilizada. 


\section{3.- Resultados}

\section{1.- Apresentação}

Os resultados permitirão responder às questões geral e específicas da investigação, a partir das quais se organizará a discussão. A sua apresentação está organizada de acordo com as seguintes categorias:

(i) verbos de comando utilizados e respetivo número de ocorrências por ano de escolaridade;

(ii)conteúdos gramaticais que são objeto de avaliação;

(iii)relação entre os itens de avaliação e as metas curriculares.

\section{(i) Verbos de comando utilizados e respetivo número de ocorrências por ano}

No $7 .^{\circ}$ ano de escolaridade, foram analisados 126 itens, nos quais foram utilizados 14 verbos ou expressões de comando, a saber: "Escreve", "Indica", "Refere", "Faz corresponder", "Transcreve", "Explicita", "Associa", "Identifica", "Reescreve", "Coloca", "Liga", "Preenche", "Classifica", "Substitui". O gráfico 1 traduz visualmente a frequência de cada um destes verbos e expressões.

\section{Gráfico 1}

Verbos e expressões de comando do $7 .^{\circ}$ ano

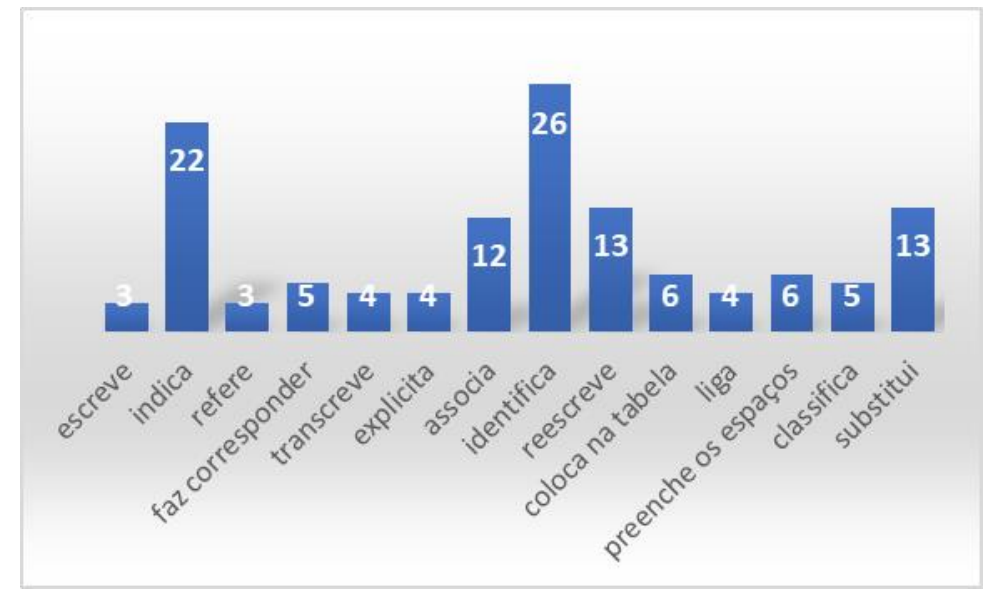

Fonte: elaboração própria. 
No $8 .^{\circ}$ ano de escolaridade, foram analisados 144 itens, nos quais foram utilizados 7 verbos de comando, a saber: "Indica", "Identifica", "Transforma", "Substitui", "Completa", "Reescreve" e "Classifica". O gráfico n. ${ }^{\circ} 2$ traduz visualmente a frequência de cada um destes verbos.

\section{Gráfico 2}

Verbos e expressões de comando do $8^{\circ}$ ano

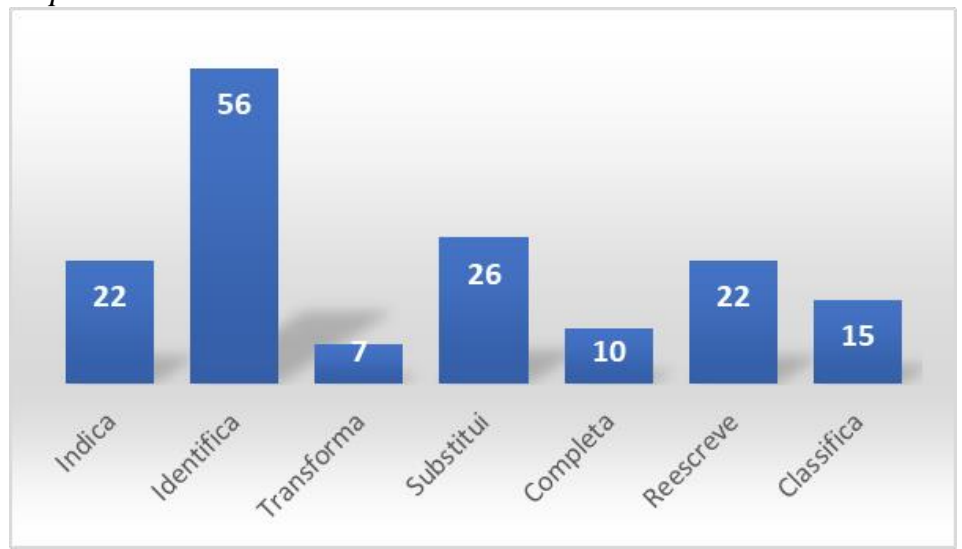

Fonte: elaboração própria

No 9. ${ }^{\circ}$ ano de escolaridade, foram analisados 175 itens, nos quais foram utilizados 7 verbos e expressões de comando, a saber: "Associa", "Classifica", "Completa", "Escreve", "Estabelece correspondência", "Identifica", "Indica", "Reescreve" e "Transforma". O gráfico n. 3 traduz visualmente a frequência de cada um destes verbos. 


\section{Gráfico 3}

Verbos e expressões de comando do 9. ${ }^{\circ}$ ano

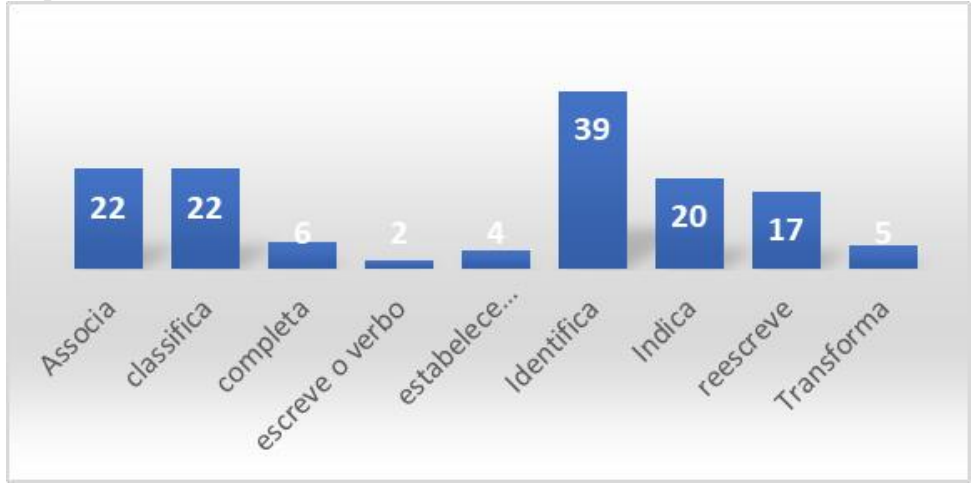

Fonte: elaboração própria

Se tomarmos em consideração uma lista organizada por ordem decrescente de utilização comparando os três anos de escolaridade em análise, obtemos o resultado apresentado na tabela 2 .

\section{Tabela 2}

Comparação dos verbos e expressões de comando nos $7 .^{\circ}, 8^{\circ}$ e $9 .^{\circ}$ anos

\begin{tabular}{|l|l|l|}
\hline $\mathbf{7 .}^{\mathbf{0}}$ ano (126 itens) & \multicolumn{1}{|c|}{${ }^{\mathbf{0}}$ ano (144 itens) } & \multicolumn{1}{|c|}{$\mathbf{9 .}^{\mathbf{0}}$ ano (175 itens) } \\
\hline Identifica (26) & Identifica (56) & Identifica (39) \\
Indica (22) & Indica (22) & Indica (20) \\
Reescreve (13) & Reescreve (22) & Reescreve (17) \\
Associa (12) & Substitui (26) & Associa (22) \\
Substitui (13) & Classifica (15) & Classifica (22) \\
Refere & Transforma & Completa \\
Faz corresponder & Completa & Escreve o verbo \\
Transcreve & & Estabelece correspondência \\
Explicita & & Transforma \\
Escreve & & \\
Coloca & & \\
Liga & & \\
Preenche & & \\
Classifica & & \\
\hline
\end{tabular}

Fonte: elaboração própria

Como poderemos verificar, a partir dos verbos predominantes, a maior parte das operações que os alunos terão de realizar são do âmbito da identificação. De facto, verbos como "identificar" e "indicar" apontam para uma operação de identificação (se excetuarmos os casos 
em que estes verbos se aplicam a operações de análise), mas também "associa", "liga" ou "estabelece a correspondência" e "faz corresponder" porque, normalmente, implicam fazer a correspondência entre duas colunas, uma que alinha unidades e a outra listas de designações de classes ou subclasses de palavras, por exemplo. Ao associarem elementos das duas colunas, os alunos estão a identificar a classe a que pertencem as palavras em destaque. O mesmo se pode dizer de "transcreve" ou de "preenche", uma vez que as tarefas indicadas pelos verbos não envolvem transformação e manipulação de elementos gramaticais de acordo com diferentes pressupostos, mas apenas identificar.

Quanto aos conteúdos gramaticais a que os dois verbos identificados como mais frequentes ocorrem associados, os resultados foram os seguintes.

O verbo "Identificar" ocorre associado a:

- funções sintáticas (21 ocorrências);

- tempo, modo, [pessoa e número] da forma verbal (8 ocorrências);

- grupos frásicos de expressões sublinhadas (6 ocorrências);

- classe e subclasse de palavras (7 ocorrências);

- frase que contém uma dada oração (17 ocorrências);

- relação semântica entre as palavras (1 ocorrência).

O verbo "Indicar" inicia as formulações de tarefas associadas a:

- $\quad$ classe e subclasse de palavras (10 ocorrências);

- classe e subclasse de verbos (5 ocorrências);

- tempo e modo verbais (5 ocorrências).

Estes dois verbos, como podemos ver, apontam para a mesma operação, que é de identificação de unidades ou funções.

"Substituir", por exemplo, ocorre sempre com "a expressão sublinhada pelo pronome correspondente" (25 ocorrências) $e$ 
“Completar" com a expressão "cada uma das frases seguintes com a forma adequada do verbo" (6 ocorrências) e "com a forma do verbo no modo e tempo indicados" (5 ocorrências). Temos, no primeiro caso, exercícios que pretendem avaliar o uso de clíticos e, no segundo, usos de tempos e modos verbais.

As classes e subclasses de palavras e as funções sintáticas centrais ocupam a maioria das questões testadas. Atente-se, em seguida, na lista dos conteúdos gramaticais que são objeto de avaliação nos testes analisados e nas operações que estão associadas a cada um deles.

\section{(ii) Conteúdos gramaticais que são objeto de avaliação}

Para efeito de exposição dos dados obtidos através da análise do corpus do nosso estudo, usamos a expressão "conteúdos gramaticais" para sintetizar os conceitos da área da gramática que estão implicados nos enunciados dos testes, embora usemos no texto o termo "conhecimento" com uma aceção idêntica, de acordo com Anderson et al. $(2014)^{7}$. Cada um dos itens de avaliação apresenta uma construção padrão que, genericamente, se pode apresentar do seguinte modo: um verbo ou expressão de comando seguida de um nome ou expressão. $\mathrm{O}$ verbo ou expressão de comando, flexionado no modo imperativo ou no presente do conjuntivo, designam a atividade a realizar pelo aluno (em geral, relacionada com um determinado processo cognitivo); o nome ou

Não é nosso objetivo neste artigo problematizar o conceito de "conteúdo" nem a relação entre os conceitos de "conteúdo" e de "conhecimento". Essa problematização é apresentada por Anderson et al. (2014). Partem da especificação do conceito de "conteúdo": «In the educational literature, content is often discussed but rarely defined. We read of content domains and disciplinar content (Doyle, 1992), content knowledge and pedagogical content knowledge (Schulman, 1987). The MerriamWebster Dictionnary (online at www.m-w.com/home) contains several definitions of content. The one most pertinent to our discussion is "matter dealt with in a field of study". This definition suggests that content is equivalent to what has traditionally been referred to as "subject matter" (that is, a content domain)» (Anderson et al., 2014, p. 12). Esclarecem o modo como se estabelece o "conteúdo" de determinado domínio disciplinar em contexto escolar e descrevem os problemas associados à utilização desse termo, que apresenta diferentes aceções no campo educacional. Terminam com a apresentação dos argumentos que sustentam a substituição do conceito de "conhecimento" pelo de "conteúdo" (Anderson et al., 2014, p. 13). 
expressão referem, em termos genéricos, o conhecimento que é esperado que o aluno domine e/ou saiba manipular para determinada atividade. No seu conjunto, o enunciado refere a tarefa a realizar. A partir dos nomes e/ou das expressões nominais (em, por exemplo, "Identifica X") ou das expressões de complementação do verbo (em, por exemplo, "Substitui X por Y"), obtivemos uma lista de conceitos que correspondem a conhecimento gramatical considerado pedagogicamente relevante ${ }^{8}$ para a aprendizagem escolar dos alunos. A tabela n. 3 apresenta os conteúdos gramaticais mobilizados nos itens analisados e a sua distribuição percentual.

\section{Tabela 3}

Conhecimentos gramaticais avaliados nos itens de $7 .^{\circ}$ ano

\begin{tabular}{lcc}
\hline \multicolumn{1}{c}{ Conteúdos gramaticais } & Número de itens em 126 & percentagem \\
\hline Operações de reconhecimento & & \\
\hline Classes e subclasses de palavras & 46 & 36,5 \\
\hline Funções sintáticas & 38 & 29,6 \\
\hline Tempos e modos dos verbos & 10 & 8 \\
\hline Orações & 6 & 4,8 \\
\hline Tipo de frase & 4 & 3,1 \\
\hline Grupos frásicos & 4 & 3,1 \\
\hline Operações de substituição e de transformação & & 10,3 \\
\hline Pronomes & 13 & 2,3 \\
\hline Verbo (voz passiva e voz ativa) & 3 & 2,3 \\
\hline Operações de expansão & & \\
\hline Família de palavras & 3 &
\end{tabular}

Fonte: elaboração própria

Tendo em conta os dados resumidos na tabela $n .^{\circ} 3$, verificamos que, no $7 .^{\circ}$ ano, o reconhecimento das classes e das subclasses de

${ }^{8}$ A relevância pedagógica é conferida pelo facto de os conteúdos ou conhecimentos gramaticais serem oficializados através de documentos de referência como Programa e Metas Curriculares (Buescu et al., 2014, 2015) e Aprendizagens Essenciais (Direção Geral de Educação, 2018a, 2018b), de materiais curriculares de apoio como o Dicionário Terminológico para Consulta em Linha (Direção Geral de Educação, 2008), de materiais instrucionais como provas e exames construídos pelas entidades responsáveis pela avaliação externa das aprendizagens dos alunos, entre outros. Além disso, a relevância pedagógica é objeto de investigação e de discussão teórico-prática em diferentes domínios científicos associados às ciências da linguagem, da pedagogia e da didática do Português. 
palavras, as funções sintáticas e os tempos e modos verbais ocupam dois terços dos itens de testagem $(74,1 \%)$. São poucas as tarefas de substituição e transformação (apenas se pede para pronominalizar e transformar voz ativa em passiva) e a única tarefa de expansão diz respeita a famílias de palavras. A morfossintaxe ocupa, portanto, um papel central e operações de reconhecimento são largamente dominantes.

Apesar de haver também um predomínio deste último tipo de operações, no $8 .^{\circ}$ ano, os itens abrangem, neste ano de escolaridade, mais conteúdos gramaticais e as operações de substituição e de transformação têm também maior peso, como se poderá verificar na tabela 4. As operações de substituição e transformação recaem, no entanto, sobre os mesmos conteúdos gramaticais do $7 .^{\circ}$ ano.

\section{Tabela 4}

Conhecimentos gramaticais avaliados nos itens do $8 .^{\circ}$ ano

\section{Operações de reconhecimento}

\begin{tabular}{lcc}
\hline Conteúdos gramaticais & Número de itens em 144 & percentagem \\
\hline Funções sintáticas & 29 & 20,1 \\
\hline Classes e subclasses de palavras & 28 & 19,4 \\
\hline Orações & 28 & 19,4 \\
\hline Tempos e modos dos verbos & 21 & 14,6 \\
\hline Grupos frásicos & 5 & 3,5 \\
\hline Relações semântica entre palavras & 2 & 1,4 \\
\hline Operações de substituição e de transformação & & 17,4 \\
\hline Pronomes & 25 & 4,1 \\
\hline Verbo (voz passiva e voz ativa) & 6 & 2,3 \\
\hline Operações de expansão & &
\end{tabular}

Fonte: elaboração própria

No que concerne ao $9 .^{\circ}$ ano, o panorama não é diferente, nem quanto ao predomínio da morfossintaxe, nem no que diz respeito ao tipo de operações solicitadas pelos diferentes itens, embora o número de itens de gramática nos testes seja maior, porventura com a aproximação dos exames de $9 .^{\circ}$ ano. Alguns conteúdos passam a ter mais relevância, por exemplo as orações. 
Tabela 5

Conhecimentos gramaticais avaliados nos itens do $9 .^{\circ}$ ano

\begin{tabular}{lcc}
\hline Operações de reconhecimento & & \\
\hline Conteúdos gramaticais & Número de itens em 175 & percentagem \\
\hline Orações & 35 & 20 \\
\hline Funções sintáticas & 30 & 17,1 \\
\hline Classes e subclasses de palavras & 28 & 16 \\
\hline Tempos e modos dos verbos & 28 & 16 \\
\hline Relações semântica entre palavras & 8 & 4,5 \\
\hline Operações de substituição e de transformação & & 6,3 \\
\hline Pronomes & 11 & 1,1 \\
\hline Verbo (voz passiva e voz ativa) & 2 &
\end{tabular}

Fonte: elaboração própria

A comparação dos dados do $7 .^{\circ}$, do $8 .^{\circ}$ e do $9 .^{\circ}$ ano permite captar os conhecimentos gramaticais que se mantêm, como conteúdo de itens de testes, durante o $3 .^{\circ}$ ciclo do ensino básico e aqueles que são especificamente valorizados em determinados anos. $\mathrm{O}$ gráfico seguinte resume, de forma mais clara, esses dados.

\section{Gráfico 4}

Conhecimentos gramaticais testados, $3^{\circ}$ ciclo

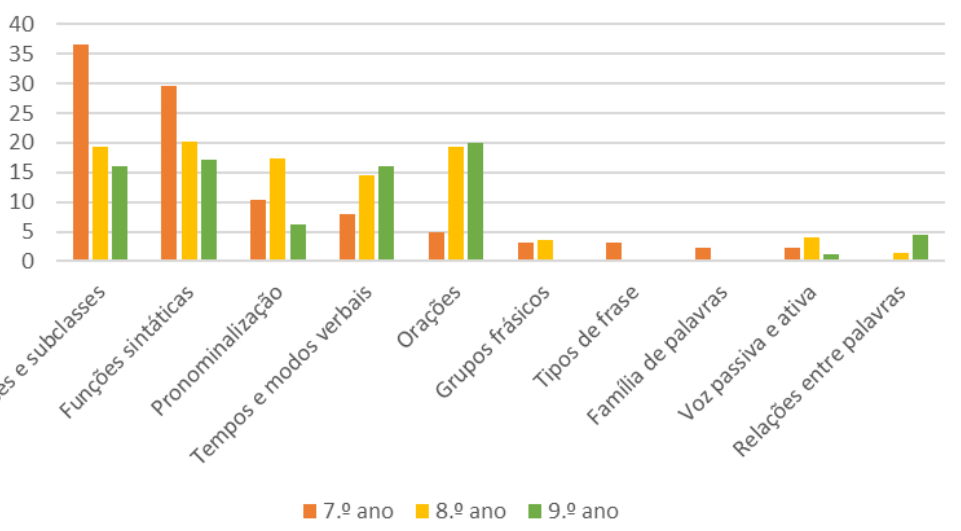

Fonte: elaboração própria 
(iii) Relação entre os itens de avaliação e as metas curriculares

A análise da relação entre os itens de avaliação e as metas curriculares contemplou duas dimensões: a primeira diz respeito às metas que são mobilizadas nos testes de cada um dos anos de escolaridade considerados; a segunda, à comparação entre o enunciado que contém a tarefa a realizar pelos alunos nos testes e a formulação da meta curricular mobilizada.

Os resultados decorrentes da análise das metas que são mobilizadas nos testes de cada um dos anos de escolaridade considerados são apresentados de seguida.

No 7. ${ }^{\circ}$ ano de escolaridade (em 126 itens analisados), a tabela $n .{ }^{\circ}$ 6 apresenta a correspondência entre os itens de avaliação e as metas curriculares do domínio da gramática, além da percentagem de itens por meta. A mancha cinzenta assinala as metas curriculares que não constituíram objeto de avaliação no corpus.

\section{Tabela 6}

7. ${ }^{\circ}$ ano de escolaridade

\begin{tabular}{|c|c|c|}
\hline Metas curriculares & $\%$ & N. ${ }^{\circ}$ \\
\hline $\begin{array}{l}\text { 21.1. Identificar e conjugar verbos em todos os tempos (simples e } \\
\text { compostos) e modos. }\end{array}$ & 7,9 & 10 \\
\hline $\begin{array}{l}\text { 21.2. Sistematizar paradigmas flexionais dos verbos regulares da } 1 .^{\mathrm{a}} \text {, } \\
\text { da } 2 .^{\mathrm{a}} \text { e da } 3 .^{\mathrm{a}} \text { conjugação. }\end{array}$ & 0 & 0 \\
\hline $\begin{array}{l}\text { 21.3. Identificar as formas dos verbos irregulares e dos verbos } \\
\text { defetivos (impessoais e unipessoais). }\end{array}$ & 0 & 0 \\
\hline $\begin{array}{l}\text { 21.4. Sistematizar padrões de formação de palavras complexas: } \\
\text { derivação (afixal e não-afixal) e composição (por palavras e por } \\
\text { radicais). }\end{array}$ & 7,9 & 10 \\
\hline 21.5. Formar o plural de palavras compostas. & 0 & 0 \\
\hline $\begin{array}{l}\text { 21.6. Explicitar o significado de palavras complexas a partir do } \\
\text { valor do radical e de prefixos e sufixos nominais, adjetivais e } \\
\text { verbais do português. }\end{array}$ & 0 & 0 \\
\hline $\begin{array}{l}\text { 22.1. Reconhecer as classes de palavras estudadas nos ciclos } \\
\text { anteriores. }\end{array}$ & 32,5 & 41 \\
\hline
\end{tabular}




\begin{tabular}{|l|c|c|}
\hline 22.2. Integrar as palavras nas classes a que pertencem ${ }^{9}$. & 0 & 0 \\
\hline $\begin{array}{l}\text { 23.1. Aplicar regras de utilização do pronome pessoal em adjacência } \\
\text { verbal }^{10} \text {. }\end{array}$ & 9,5 & 12 \\
\hline $\begin{array}{l}\text { 23.2. Consolidar o conhecimento sobre as funções sintáticas } \\
\text { estudadas no ciclo anterior. }\end{array}$ & 25,4 & 32 \\
\hline $\begin{array}{l}\text { 23.3. Identificar o sujeito subentendido e o sujeito indeterminado. } \\
\text { 23.4. Transformar frases ativas em frases passivas e vice-versa } \\
\text { (consolidação). }\end{array}$ & 0 & 0 \\
\hline $\begin{array}{l}\text { 23.5. Transformar discurso direto em indireto e vice-versa (todas as } \\
\text { situações). }\end{array}$ & 0 & 0 \\
\hline 23.6. Identificar processos de coordenação entre orações ${ }^{11}$. & 4 & 5 \\
\hline 23.7. Identificar processos de subordinação entre orações ${ }^{12}$. & 1,6 & 2 \\
\hline 23.8. Identificar oração subordinante. & 0 & 0 \\
\hline \multicolumn{1}{|c|}{ Total } & 91,2 & 115 \\
\hline
\end{tabular}

Fonte: elaboração própria

Os campos com indicador mais elevado são o 22.1. e o 23.2., ambos referentes a aprendizagens "estudadas nos ciclos anteriores.". Este resultado revela preocupação com aprendizagens em curso que, apesar de introduzidas e trabalhadas nos ciclos anteriores (o 1..$^{\circ}$ ciclo constituído por 4 anos letivos e o $2 .^{\circ}$ ciclo, por 2 anos letivos), não estão ainda consolidadas.

\footnotetext{
9 As classes em causa são as seguintes: verbo principal: transitivo direto, transitivo indireto, transitivo direto e indireto; advérbio: valores semânticos - de dúvida, de inclusão, de exclusão, de designação; funções - relativo e conectivo; determinante: indefinido, relativo, interrogativo; pronome relativo; conjunção coordenativa: copulativa, adversativa, disjuntiva, conclusiva e explicativa; conjunção subordinativa: causal e temporal; locução: prepositiva e adverbial.

${ }^{10}$ Os contextos são os seguintes: em frases afirmativas; em frases que contêm uma palavra negativa; em frases iniciadas por pronomes e advérbios interrogativos; com verbos antecedidos de certos advérbios (bem, mal, ainda, já, sempre, só, talvez...).

${ }_{11}$ Os processos de coordenação dizem respeito a: orações coordenadas copulativas (sindéticas e assindéticas), adversativas, disjuntivas, conclusivas e explicativas.

${ }_{12}$ Os processos de subordinação dizem respeito a: subordinadas adverbiais causais e temporais; subordinadas adjetivas relativas.
} 
No 8..$^{\circ}$ ano de escolaridade (em 144 itens analisados), os dados que relacionam os itens de avaliação dos testes analisados com as metas curriculares são apresentados na tabela n. $^{\circ} 7$.

\section{Tabela 7}

8. ${ }^{\circ}$ ano de escolaridade

\begin{tabular}{|c|c|c|}
\hline Metas curriculares & $\%$ & N. ${ }^{\circ}$ \\
\hline 23.1. Integrar as palavras nas classes a que pertencem ${ }^{13}$. & 2 & 3 \\
\hline $\begin{array}{l}\text { 24.1. Aplicar as regras de utilização do pronome pessoal em adjacência } \\
\text { verbal: em orações subordinadas; na conjugação do futuro e do } \\
\text { condicional. }\end{array}$ & 10,4 & 15 \\
\hline $\begin{array}{l}\text { 24.2. Identificar as funções sintáticas de modificador do nome } \\
\text { (restritivo e apositivo). }\end{array}$ & 10,4 & 15 \\
\hline 24.3. Identificar processos de subordinação entre orações ${ }^{14}$. & 12,5 & 18 \\
\hline $\begin{array}{l}\text { 24.4. Estabelecer relações de subordinação entre orações, identificando } \\
\text { os elementos de que dependem as orações subordinadas. }\end{array}$ & 0 & 0 \\
\hline 24.5. Dividir e classificar orações. & 0 & 0 \\
\hline 25.1. Identificar neologismos. & 0 & 0 \\
\hline 25.2. Identificar palavras polissémicas e seus significados. & 0 & 0 \\
\hline 25.3. Distinguir palavras polissémicas de monossémicas. & 0 & 0 \\
\hline $\begin{array}{l}\text { 25.4. Determinar os significados que dada palavra pode ter em função } \\
\text { do seu contexto de ocorrência: campo semântico. }\end{array}$ & 0 & 0 \\
\hline $\begin{array}{l}\text { 25.5. Reconhecer e estabelecer as seguintes relações semânticas: } \\
\text { sinonímia, antonímia, hiperonímia e holonímia. }\end{array}$ & 1,4 & 2 \\
\hline Total & 36,7 & 33 \\
\hline
\end{tabular}

Fonte: elaboração própria

Os dados que relacionam os itens de avaliação dos testes analisados com as metas curriculares do $9 .^{\circ}$ ano de escolaridade (em 175 itens analisados) estão contidos na tabela n. ${ }^{\circ} 8$.

\footnotetext{
${ }^{13}$ As classes em causa são as seguintes: advérbio: de dúvida, de designação e relativo; conjunção subordinativa: condicional, final, comparativa, consecutiva, concessiva e completiva; locução conjuncional.

${ }^{14}$ Os processos de subordinação são os seguintes: subordinadas adverbiais condicionais, finais, comparativas, consecutivas e concessivas; subordinadas substantivas completivas (função de complemento direto).
} 


\section{Tabela 8}

9. ${ }^{\circ}$ ano de escolaridade

\begin{tabular}{|l|c|c|}
\hline \multicolumn{1}{|c|}{ Metas curriculares } & $\%$ & N. $^{\text {o }}$ \\
\hline $\begin{array}{l}\text { 24.1. Identificar processos fonológicos de inserção (prótese, epêntese } \\
\text { e paragoge), supressão (aférese, síncope e apócope) e alteração de } \\
\text { segmentos (redução vocálica, assimilação, dissimilação, metátese). }\end{array}$ & 3,4 & 6 \\
\hline $\begin{array}{l}\text { 25.1. Sistematizar as regras de utilização do pronome pessoal em } \\
\text { adjacência verbal em todas as situações. }\end{array}$ & 6,3 & 11 \\
\hline 25.2. Consolidar o conhecimento de todas as funções sintáticas. & 17,1 & 30 \\
\hline 25.3. Identificar orações substantivas relativas. & 0,6 & 1 \\
\hline 25.4. Dividir e classificar orações. & 1,1 & 2 \\
\hline 26.1. Identificar neologismos e arcaísmos. & 0 & 0 \\
\hline \multicolumn{1}{|c|}{ Total } & 28,5 & 50 \\
\hline
\end{tabular}

Fonte: elaboração própria

As tabelas n. ${ }^{\circ} 6$, n. $^{\circ} 7$ e n. 8 mostram que as metas curriculares de cada ano de escolaridade não esgotam a totalidade dos itens de avaliação dos testes, havendo em cada um deles espaço para as metas de anos de escolaridade anteriores àqueles em que os alunos estão inscritos. Ou seja, uma parte do ensino da gramática consiste em rever o que já foi ensinado em anos anteriores. Esta tendência é mais vincada no $8 .^{\circ}$ e no $9 .^{\circ}$ ano, embora sejam anos em que se introduzem, também, itens gramaticais novos. A tabela $n^{\circ} 9$ procura sintetizar esses dados.

\section{Tabela 9}

Comparação da percentagem de metas curriculares mobilizadas em cada ano de escolaridade

\begin{tabular}{lc:c}
\hline $\begin{array}{c}\% \text { de itens relacionados com metas } \\
\text { do ano que os alunos estão a } \\
\text { frequentar }\end{array}$ & $\begin{array}{l}\text { \% de itens relacionados com metas } \\
\text { do(s) ano(s) anterior(es) ao que os } \\
\text { alunos estão a frequentar }\end{array}$ \\
\hline $\mathbf{7 .}^{\mathbf{0}}$ & 91,2 & 8,8 \\
\hline $\mathbf{8 .}^{\mathbf{0}}$ & 36,7 & 63,3 \\
\hline $\mathbf{9 .}^{\mathbf{0}}$ & 28,5 & 71,5 \\
\hline
\end{tabular}

Fonte: elaboração própria

Para comparar os enunciados que, nos testes de avaliação, indicam a tarefa a realizar pelos alunos e o modo como a meta curricular mobilizada está formulada, foram analisados os casos correspondentes aos itens com taxa de frequência mais elevada em cada um dos anos de escolaridade. Os dados obtidos são apresentados de seguida. 


\section{Tabela 10}

Comparação dos itens de avaliação dos testes do $7^{\circ}$ ano com a meta curricular equivalente

\section{Meta curricular}

22.1. Reconhecer as classes de palavras estudadas nos ciclos anteriores.

\section{Itens de avaliação de testes do $7 .^{\circ}$ ano}

a) Identifica a classe e subclasse das palavras destacadas.

b) Indica a(s) subclasse(s) de palavras...

c) Identifica o verbo nas frases que se seguem e indica a subclasse a que pertence.

d) Indica a subclasse dos verbos (...).

e) Transcreve do slogan dois nomes comuns.

f) Associa a palavra sublinhada nas frases da coluna A à classe e subclasse que lhe correspondem na coluna B.

g) Coloca, na tabela, as palavras das duas frases que se seguem de acordo com a classe a que pertencem.

h) A única frase que integra um pronome demonstrativo é...

Fonte: elaboração própria

A capacidade de reconhecimento das classes de palavras é avaliada através de tarefas de construção de resposta curta (alíneas a, b, c, d da tabela 10) e de seleção por completamento (alíneas e, g e h da tabela 10) e por associação (alínea f da tabela 10).

\section{Tabela 11}

Comparação dos itens de avaliação dos testes do $8 .^{\circ}$ ano com a meta curricular equivalente

\section{Meta curricular}

24.1. Aplicar as regras de utilização do pronome pessoal em adjacência verbal

\section{Itens de avaliação de testes do $8 .^{\circ}$ ano}

i) Substitui a expressão sublinhada pelo pronome correspondente.

j) Reescreve a frase abaixo, substituindo as expressões sublinhadas pelas formas adequadas do pronome pessoal. Faz as alterações necessárias.

Fonte: elaboração própria

Os 25 itens relacionados com a pronominalização nos testes do 8. $^{\circ}$ ano de escolaridade (144 itens) alternam entre a formulação i) e j) (tabela 11), que se repetem também nos testes do $9 .^{\circ}$ ano. 
As tarefas relacionadas com a análise das funções sintáticas são enunciadas através de formulações como as que se apresentam na tabela n. ${ }^{\circ} 12$.

\section{Tabela 12}

Comparação da formulação de itens de avaliação e de metas curriculares

\begin{tabular}{|c|c|c|}
\hline \multirow{3}{*}{$\begin{array}{l}\text { Metas } \\
\text { curriculares }\end{array}$} & 7..$^{\circ}$ & $\begin{array}{l}\text { 23.2. Consolidar o conhecimento sobre as funções sintáticas } \\
\text { estudadas no ciclo anterior }{ }^{15} \text {. }\end{array}$ \\
\hline & $8 .^{\circ}$ & $\begin{array}{l}\text { 24.2. Identificar as funções sintáticas de modificador do nome } \\
\text { (restritivo e apositivo). }\end{array}$ \\
\hline & $9 .^{\circ}$ & 25.2. Consolidar o conhecimento de todas as funções sintáticas. \\
\hline \multirow{3}{*}{$\begin{array}{l}\text { Itens do } \\
\text { corpus }\end{array}$} & $7 .^{\circ}$ & $\begin{array}{l}\text { k) Faz corresponder cada constituinte destacado na coluna A à } \\
\text { única opção correta da coluna B (funções sintáticas). } \\
\text { 1) Indica as funções sintáticas da frase } X \text {. } \\
\text { m) Identifica nas alíneas que se seguem as funções sintáticas das } \\
\text { expressões sublinhadas. } \\
\text { n) Indica a função sintática dos constituintes destacados. }\end{array}$ \\
\hline & $8 .^{\circ}$ & $\begin{array}{l}\text { o) Identifica as funções sintáticas das palavras sublinhadas. } \\
\text { p) Identifica as funções sintáticas desempenhadas por cada uma } \\
\text { das expressões sublinhadas. } \\
\text { q) Identifica as funções sintáticas dos constituintes sublinhados } \\
\text { nas frases, fazendo a correspondência entre os elementos da } \\
\text { coluna A e dos da coluna B. }\end{array}$ \\
\hline & $9 .^{\circ}$ & $\begin{array}{l}\text { r) Estabelece a correspondência entre as palavras sublinhadas } \\
\text { nas frases da coluna A e as funções sintáticas indicadas na } \\
\text { coluna B. } \\
\text { s) Identifica as funções sintáticas desempenhadas pelos } \\
\text { constituintes sublinhados. } \\
\text { t) Indica a função sintática de cada um dos segmentos frásicos } \\
\text { sublinhados nas frases que se seguem. } \\
\text { u) Identifica as funções sintáticas desempenhadas pelos } \\
\text { constituintes sublinhados. }\end{array}$ \\
\hline
\end{tabular}

Fonte: elaboração própria

15 Sujeito (simples e composto), vocativo, predicado, complemento direto, complemento indireto, complemento oblíquo, complemento agente da passiva, predicativo do sujeito, modificador. 


\section{2.- Discussão}

Os resultados obtidos pela análise crítica do corpus, constituído por itens avaliativos do conhecimento explícito da língua, contidos em testes produzidos e aplicados por professores de uma escola pública às turmas de $7 .^{\circ}, 8^{\circ}$ e $9 .^{\circ}$ anos de escolaridade, permitem esclarecer as questões específicas de partida. A discussão dos resultados tomará, assim, como referência cada uma delas.

O propósito da primeira questão consistia em conhecer as aprendizagens gramaticais que são objeto de avaliação pelos professores de Português, no domínio do conhecimento explícito da língua, no $3 .^{\circ}$ ciclo do ensino básico. Os resultados permitem identificar duas categorias de aprendizagens: uma associada ao objetivo da tarefa e à operação cognitiva inerente; outra ligada aos conceitos gramaticais com que era necessário operar na realização da tarefa.

Quanto às tarefas (e, consequentemente às operações cognitivas), foi possível identificar um número limitado de verbos de comando e um conjunto de formulações repetidas nos testes ao longo de cada um dos anos, desde o 7..$^{\circ}$ ao $9 .^{\circ}$. Retomando os dados da tabela $n .^{\circ}$ 2 , relativamente aos quais foram subtraídas as repetições e excluídas as formulações indicativas do modo como a resposta deveria ser dada pelo aluno ("associa", "liga", "faz a correspondência", "coloca"), obtém-se um conjunto de tarefas associadas a cinco operações cognitivas: identificar ("Identifica", "Indica", "Escreve [o verbo]", "Transcreve", "Refere"), classificar ("Classifica"), explicitar/explicar ("Explicita"), produzir ("Escreve", "Completa"), substituir ("Substitui", "Transforma", "Reescreve").

Deste conjunto de atividades, as que apresentam menor expressão são as que envolvem manipulação relacionada com diferenças de forma e significado. Quando se pede para manipular e transformar, na esmagadora maioria das vezes, é para transformar de voz ativa em passiva, sem atentar nos eventuais efeitos das mudanças, ou para substituir palavras ou grupos por pronomes, querendo-se, 
apenas, testar se o aluno conhece as regras de colocação dos clíticos em português europeu.

Estes resultados não são surpreendentes, tendo em conta trabalhos centrados na análise de atividades gramaticais propostas em manuais escolares, como o de Olave (2011) e o de Fabienne Vernet (Univ. de Grénoble) no âmbito da formação de professores. Sobressai deste último um conjunto de oito verbos que permitem categorizar as tarefas solicitadas aos alunos no âmbito do ensino da gramática: "Identifier", "Classer", "Trier", "Comparer", "Définir", "Modifier", "Mettre en relation", "Justifier" (Vernet, s/d). No seu estudo, Olave (2011) mostrou como, das categorias tidas em conta, "los ejercicios que propenden por la identificación de elementos gramaticales al interior de un texto se perfilan como los más recurrentes con un 33,26\% de incidencia [...]." (p. 41).

Apesar de não serem surpreendentes, dado que é conhecida a importância da categorização e da estruturação de conhecimento gramatical basilar na escolaridade obrigatória, não deixa de constituir objeto de reflexão o facto de haver uma repetição contínua e sistemática das mesmas tarefas ao longo dos três anos analisados: integrar palavras nas suas classes e subclasses, classificar estruturas frásicas, identificar as funções sintáticas centrais, conjugar verbos em diferentes tempos e modos. Esta repetição, sem evidência de complexidade progressiva, corre o risco de mecanização e automatização das tarefas, contribuindo para a desmotivação dos alunos e para o esvaziamento da reflexão sobre a língua.

Além disso, as tarefas solicitadas são baseadas em elementos e estruturas descontextualizadas, com poucos exercícios em que o contexto e o cotexto tenham influência nas escolhas (apenas alguns itens de preenchimento de espaços com tempos e modos verbais, exigidos pela consecutio temporum, por exemplo, contextos de uso obrigatório de conjuntivo).

Quanto aos conceitos gramaticais com os quais o aluno opera na realização da tarefa, os resultados mostram que há um núcleo de 
conhecimentos gramaticais que se repete anualmente ao longo do $3 .^{\circ}$ ciclo do ensino básico. Esse núcleo é constituído por cinco conteúdos específicos: classes e subclasses de palavras, flexão verbal, funções sintáticas, pronominalização e classificação de orações.

Os resultados mostram ainda que à repetição de tarefas e conteúdos evidenciada se associa a acumulação, já que do $7 .^{\circ}$ até ao $9 .^{\circ}$ ano se verifica um progressivo aumento do número de itens de avaliação do conhecimento gramatical em cada teste.

Apesar de a secção de cada teste de Português relativa à gramática conter sempre de 3 a 5 itens, à medida que se passa do $7 .^{\circ}$ para o $8 .^{\circ}$ e do $8 .^{\circ}$ para o $9 .^{\circ}$ ano, existe um desdobramento de cada um desses itens em subitens. Através deste desdobramento, o teste mantém a estrutura predeterminada (de 3 a 5 itens para a gramática), embora, na verdade, se proceda a uma ampliação das tarefas relacionadas com o conhecimento explícito da língua/gramática. Torna-se evidente a lógica cumulativa ao longo do $3 .^{\circ}$ ciclo do ensino básico.

Acresce a isso o facto de o conhecimento mobilizado para cada um dos tópicos gramaticais referido ser pouco complexo. Veja-se, por exemplo, as tarefas relacionadas com a pronominalização: nos três anos de escolaridade considerados, são pedidos os casos mais óbvios e fáceis, com o clítico quase sempre em adjacência verbal à direita e poucas vezes os casos muito óbvios de próclise em contexto de negação, mas quase nunca outros contextos de próclise obrigatória que sejam de aplicação menos automática e pouquíssimas vezes casos de mesóclise. Por outro lado, alguns dos exemplos pedidos configuram casos em que a aquisição é suficiente para os alunos resolverem a pergunta. Se se pede ao aluno que substitua a expressão sublinhada por um pronome em "Ele vai comer o bolo", é óbvio que responderá "Ele vai comê-lo", porque é assim que diz (e nunca *comer-lo). No 8. ${ }^{\circ}$ ano, por exemplo, não há nenhuma questão em que o clítico seja usado "em orações subordinadas" e poucas perguntas implicam usá-lo "na conjugação do futuro e do condicional". 
Verificou-se ainda que há poucas ou nenhumas tarefas relacionadas com a área da semântica e do léxico, apesar da importância que poderiam ter para melhorar o desempenho dos alunos quanto, por exemplo, à competência de leitura. Há também uma consideração isolada de cada plano gramatical; por exemplo, não se liga a sintaxe à semântica, procurando ver que implicações de sentido advêm das alterações das formas.

O propósito da segunda questão específica consistia no estabelecimento de uma relação entre os itens de avaliação do conhecimento da língua dos testes dos professores, as metas curriculares da disciplina de Português e os itens das provas de avaliação externa.

Os resultados mostram que as aprendizagens curriculares com quase total representação nos testes de avaliação analisados dizem respeito ao plano da classe de palavras, da morfologia flexional e da sintaxe, numa perspetiva sistémica de identificação e classificação de unidades de cada nível linguístico (análise de constituintes, análise de funções, classificação de palavras, classificação de orações).

Revelam ainda duas tendências que importa assinalar: (i) um desfasamento temporal entre o currículo prescrito e o currículo implementado pelo professor, uma vez que as aprendizagens enunciadas para o $7 .^{\circ}$ ano surgem nos testes do $8 .^{\circ}$; as do $8 .^{\circ}$, ocorrem no $9 .^{\circ}$, ano em que a acumulação de tarefas gramaticais por teste é maior; (ii) uma insistência prolongada ao longo de vários anos escolares de determinadas aprendizagens (tarefas e conteúdos gramaticais) para além do nível de ensino ao qual o currículo prescrito as associa. Estas tendências são reveladoras da gestão que os professores fazem do currículo em função do contexto real, do grau de desenvolvimento das aprendizagens dos alunos e da dificuldade de tornar efetivo um núcleo de aprendizagens consideradas relevantes e úteis para os alunos. Sugerem uma preocupação com a consolidação e a rememoração de conhecimentos. Mesmo que o currículo prescrito defina para o $7 .^{\circ}$ ano de escolaridade a aprendizagem inerente à capacidade de "Identificar processos de subordinação entre orações", em particular de "orações 
subordinadas adjetivas relativas", essa referência marca o início do processo de desenvolvimento dessa capacidade, não o seu fim. $\mathrm{O}$ final será determinado pelo juízo avaliativo do professor perante a constatação de que a aprendizagem está consolidada para os seus alunos. Enquanto essa verificação não ocorrer, se considerar a aprendizagem como relevante e necessária, ela continuará a ser objeto de ensino-aprendizagem e, consequentemente, objeto de avaliação nos testes.

Dos resultados infere-se ainda a transposição quase literal dos enunciados das metas curriculares, que passam de objetivos de aprendizagem nesse documento orientador para instruções de realização de tarefas, nos testes de avaliação, em que ocorrem quase ipsis verbis. A comparação estabelecida nas tabelas 10, 11 e 12 torna evidente esse mimetismo: a título exemplificativo, veja-se a similitude da meta 24.2., do $8 .^{\circ}$ ano, "Identificar as funções sintáticas de modificador do nome (restritivo e apositivo).", e itens como "Identifica as funções sintáticas das palavras sublinhadas." (itens o), p), q) da tabela 12).

Idêntico mimetismo ocorre entre os itens do corpus analisado e os exames nacionais. Os resultados aqui apresentados são compatíveis com as investigações citadas inicialmente (Rei, 2004; Silva, 2009; Silva \& Sousa, 2009; Silva \& Silva, 2011; Rio-Torto, 2011; Tapadas, 2016; Rodrigues, 2019), em particular com o trabalho de Tapadas (2016), que analisa os itens de avaliação gramatical das provas de avaliação externa dos últimos 10 anos. Esta proximidade de resultados dá consistência à descrição da situação atual do ensino da gramática em Portugal. Ora, como se sabe, os exames e demais provas de avaliação têm um efeito condicionante sobre a conceção dos testes que os professores aplicam, sobre as questões em que insistem nas aulas, sobre as metodologias de ensino-aprendizagem que ativam e até sobre os conteúdos gramaticais selecionados. 


\section{Conclusões}

Através do estudo realizado, baseado no corpus descrito, provase que a avaliação interna do conhecimento gramatical dos alunos mediante testagem é baseada em itens avaliativos que mantêm com as metas curriculares e com as provas de avaliação externa um mimetismo absoluto não só em relação ao núcleo de conhecimentos valorizados sobretudo classes de palavras, morfologia e sintaxe (constituintes, funções sintáticas, orações) -, mas também à redação dos enunciados que expressam as tarefas solicitadas aos alunos em cada item.

Comprova-se, portanto, que os professores optam por elaborar e aplicar como instrumento de avaliação pedagógica do conhecimento gramatical desenvolvido nas aulas itens avaliativos estandardizados extraídos, adaptados ou construídos à imagem das provas de avaliação externa, promovendo um "estreitamento" curricular das aprendizagens ligadas à competência metalinguística. Comprova-se também que as metas curriculares são apropriadas como tarefas a treinar até uma resposta automática correta em prova de avaliação externa, em vez de funcionarem como referência de uma competência a desenvolver nos alunos, mediante estratégias de ensino diversificadas. Nesta medida, contribuem também para um "estreitamento" das estratégias de ensino e das atividades selecionadas para os alunos realizarem ao longo do ano.

É certo que o estudo aqui apresentado se circunscreve a um caso (uma escola concreta com o seu contexto específico), não nos autorizando, portanto, a uma generalização. No entanto, engloba uma amostra autêntica representativa de itens de avaliação gramatical (445 itens referentes a um ano letivo) e faculta dados suficientes para uma descrição válida e fiável da realidade que foi objeto de análise (avaliação do conhecimento gramatical dos alunos). Permite ainda compreender as opções dos professores de Português na gestão do currículo oficial da disciplina, no que se refere ao ensino-aprendizagem da gramática.

Oferece matéria bastante para uma reflexão em torno da didática da gramática no que diz respeito à avaliação interna (técnicas, 
procedimentos, instrumentos), componente fundamental da aprendizagem.

\section{Agradecimentos}

Nenhum trabalho de reflexão e de investigação centrado em sala de aula pode ser realizado sem a generosa colaboração dos professores que diariamente trabalham nas nossas escolas para educarem os alunos de acordo com os princípios estabelecidos pela sociedade. Este nosso trabalho nunca teria sido possível sem a colaboração de todos os profissionais que ensinam Português, no Agrupamento de Escolas de Vilela, nem a do seu Diretor, Dr. Albino Pereira, que sempre compreendeu o valor da investigação baseada em aula. Este reconhecimento público por toda a generosidade e colaboração é também uma prova do quanto se aprende quando se observam aulas e se analisam documentos internos do exercício da docência.

Agradecemos aos avaliadores anónimos deste artigo pelos comentários e observações.

\section{Referências bibliográficas}

Anderson, L., Krathwohl D., Airasian P., Cruikshank K., Mayer R., Pintrich P., Wittrock, M. (2014). A taxonomy for learning, teaching, and assessing: a revision of Bloom's. Essex: Pearson Education.

Barbosa, J. y Neves, A. (2006). Fantasmas, Mitos e Ritos da Avaliação das Aprendizagens. Revista Portuguesa de Pedagogia, 40 (3), 219-235.

Buescu, H., Maia, L., Silva, M. G., y Rocha, M. R. (2014). Programa e metas curriculares de Português do ensino secundário. Lisboa: Ministério da Educação, Direção Geral de Educação.

Buescu, H., Morais, J., Rocha, M. R., y Magalhães, V. (2015). Programa e metas curriculares de Português do ensino básico. Lisboa: Ministério da Educação, Direção Geral de Educação.

Costa, A.L. (2020). Grammar Teaching 91-19: An analysis of the Portuguese curricula. L1-Educational Studies in Language and Literature, 20, 1-31. https://doi.org/10.17239/L1ESLL-2020.20.03.03 
Direção Geral de Educação (2008). Dicionário terminológico para consulta em linha (DT). Ministério da Educação, Direção Geral de Educação. Recuperado de: http://dt.dge.mec.pt/

Direção Geral de Educação (2018a). Aprendizagens essenciais do ensino básico. Lisboa: Ministério da Educação, Direção Geral de Educação. Recuperado de: https://www.dge.mec.pt/aprendizagensessenciais-ensino-basico

Direção Geral de Educação (2018b). Aprendizagens essenciais do ensino secundário. Lisboa: Ministério da Educação, Direção Geral de Educação. Recuperado de: http://www.dge.mec.pt/aprendizagensessen-ciais-ensino-secundario

Duarte, I. M; Rodrigues, S. V.; Machado, A.; Guedes, M. M., y Toriz, H. (2016). A escrita escolar para expressão de conhecimentos e aprendizagens: um caso em estudo. $V$ Simpósio Internacional em Ensino de Língua Portuguesa / V Fórum Ibero-Americano de Literacias. Atas (pp. 219-232). Braga: Universidade do Minho, CIED.

Fernandes, D. (2015). Prefácio. In A. C. Neves y A. L. Ferreira, Avaliar é preciso? Guia prático para professores e formadores (pp. 1315). Lisboa: Guerra \& Paz.

Fernandes, D. (2019). Avaliações externas e aprendizagens dos alunos: uma reflexão crítica. Linhas Críticas, 25, 644-660.

Neves, A. C., y Ferreira, A. L. (2015). Avaliar é preciso? Guia prático para professores e formadores. Lisboa: Guerra \& Paz.

Olave, G. (2011). La gramática al tablero: ejercicios de gramática en los manuales escolares de básica secundaria, Encuentros, 2, 37-49.

Pacheco, J. A. (2001). Currículo: teoria e praxis (2. ${ }^{\text {e ed.) Porto: }}$ Porto Editora.

Peralta, H. (2002). Como avaliar competência(s)? Algumas considerações. In P. Abrantes y F. Araújo (Coord.), Reorganização curricular do ensino básico. Avaliação das aprendizagens - das concepções às práticas (pp. 25-34). Lisboa: Ministério da Educação/Departamento da Educação Básica.

Rei, J. E. (2004). O ensino da gramática no liceu, através da análise dos exames nacionais, dos anos 30 aos anos 90 do século XX, em Portugal. In Aurora Marco et al. (Eds.), Actas del VII Congreso Internacional de la Sociedad Española de Didáctica de la Lengua y la 
Literatura (pp. 475-485). A Coruña: Deputation Provincial de A Coruña.

Resnick, L. B. (1987). Education and learning to think. Washington, DC: The National Academy Press.

Roldão, M. C. (1999). Os professores e a gestão do currículo. Perspetivas e práticas em análise. Porto: Porto Editora.

Roldão, M. C., y Almeida, S. (2018). Conhecimento e currículo: como se seleciona o conhecimento "relevante"? In J. A. Pacheco, M. C. Roldão y M. T. Estrela (Orgs.), Estudos de currículo (pp. 89-127). Porto: Porto Editora.

Rio-Torto, G. (2011). Avaliação em língua portuguesa nos exames nacionais de $9 .^{\circ}$ ano. In M. T. Mingocho, M. F. Gil y M. E. Castendo (Eds.), Miscelânea de estudos em homenagem a Maria Manuela Gouveia Delille (pp. 683-718). Vol. I. Coimbra: Edições Minerva Coimbra.

Rodrigues, S. (2017). O ensino do português nas primeiras décadas do século XXI. In A. Canelas et al. (Eds.), Lei de Bases do Sistema Educativo. Balanço e Prospetiva (pp. 247-291). Vol. II. Lisboa: Conselho Nacional de Educação.

Rodrigues, S. V. (2019). Conhecimento gramatical avaliado à saída da escolaridade obrigatória: uma análise de exames nacionais do ensino secundário. Revista da Associação Portuguesa de Linguística (6), 41-64. DOI: https://doi.org/10.26334/2183-9077/rapln6ano2019a5

Rodrigues, S. V.; Duarte, I. M., y Silvano, P. (2018). O verbo Explicar em enunciados de testes de avaliação do ensino básico: estudo de valores semânticos e pragmáticos. In J. Veloso, J. Guimarães, P. Silvano y R. Silva (Eds.), A linguística em diálogo. Volume comemorativo dos 40 anos do Centro de Linguística da Universidade do Porto (pp. 361-394). Porto: FLUP/CLUP.

Silva, A. C. (2009). A natureza e os fins do conhecimento gramatical: análise de provas de exame de Português, Diacrítica Ciências da Linguagem, 23 (1), 171-203.

Silva, A. C., y Sousa, J. E. (2009). Sobre a avaliação do conhecimento gramatical escolar: um estudo dos exames nacionais de português de 2009. In J. C. Morgado, M. P. Alves, S. S. Pillotto y M. I. Cunha (Eds), Aprender ao longo da vida - contributos, perspectivas e questionamentos do currículo e da avaliação (Actas do $2^{\circ}$ Congresso 
Internacional sobre Avaliação em Educação) (pp. 3986-3999). Braga: Centro de Investigação em Educação, Instituto de Educação e Universidade do Minho.

Silva, A. C., y Silva, A. P. (2011). A avaliação do conhecimento gramatical "oficial": estudo dos exames nacionais de Português de 2010, Atas do 2. ${ }^{\circ}$ Congresso Internacional sobre Avaliação em Educação (pp. 1352-1364). Universidade do Minho, Instituto de Educação.

Tapadas, P. J. (2016). Qual o histórico de itens gramaticais? Seminário "Avaliar o conhecimento gramatical". Faculdade de Letras de Universidade de Lisboa. 15 de fevereiro de 2016.

Vernet, F. (s/d). Operations mentales effectuées par les élèves. Recuperado de http://www.acgrenoble.fr/ien.g4/IMG/pdf_pdf_Grille_analyse_consignes.pdf 
Tejuelo, nº 35.2 (2022), págs. 137-172. Avaliação do conhecimento explícito da língua... 